\title{
A Group-specific Substance of Lipoid Nature in a Liver Metastasis of Gastric Cancer.
}

First Report.*

By

\section{Mașasiroh Aikawa.}

(會们正四郎)

(From the Medico-chemical Institute (Director: Prof. $\mathrm{H}$. Masamune) and Medical Clinic of Prof. T. Kurokawa, Tohoku University, Sendai.)

(Received for publication, November 9, 1948)

It will be of importance to decide whether or not group-specific substances are present in malignant tumors, which take an immature embryonic type of tissue, because fetus in the earlier stages of development exhibit no group specifity as is known. Oh-Uti,1) a colleague of mine, isolated from stomach cancers, carbohydrates and a glycidamin which were of a low grade of differentiation in the mentioned aspect. The present account deals with an active lipoid in this kind of malignant tumor. The material was a liver metastasis of gastric cancer. There were obtained fractions specifically inhibitory to the isoagglutination of $\mathbf{B}$ erythrocytes (the patient belonged to Group B). The activity of four fractions finally obtained was recognized at a dilution of 1:800 in one of them and in the others at a dilution of $1: 1600$. Early fractions inhibited the agglutination but non-specificaily, and the specifity became manifest in the later ones. This is comparable to the observations of Lattes et $\mathrm{al}^{2 y}$ as well as of Eisler and Moritsch" ${ }^{31}$ on the extracts of erythrocytes. The final fractions above showed different solubilities, one being soluble in almost all organic solvents and insoluble in water and the others soluble only in a few organic solvents such as benzene, chloroform and hot tetralin but very readily in water. Each of them contained nitrogen and phosphorus and gave Thudicum's reaction for psychosin and Molisch's for sugar, all in accord with the findings by Hamasato ${ }^{4)}$ on the group lipoids from erythrocytes. Quantitative-analytically, however, they diverged from one another markedly. Their approximate equivalent ratios of sugar as galactose : phosphorus : nitrogen were found $1: 5: 10 ; ?: 1: 8 ; 1: 2: 9 ; 1: 1: 3$. The preparation possessing the equivalent ratios at the end of the com-

\footnotetext{
* Ist report of Masamune and co-workers' Chemistry and Biology of Lipoids.
} 
ponents was most water-soluble and contained the largest amount of sugar, viz., $17.5 \%$. Inferences from the above results will be described in the paragraph of discussion. I examined also if lipoid fractions of the tumor give rise to hemolysis whose ditails will be given in the experimental part.

It ought to be added here that investigations of group lipoids from other sources than erythrocytes have never before been made.

\section{EXPERIMENTAL.}

Procedure of Fractionation and the Anti-agglutinative Potency of the Fractions.

A large matastasis in liver of gastric cancer (the person belonged to Group B), weighing 2200 gm., were cut into small pieces, washed with water to free from blood and masticated. The pieces were placed in $1.5 l$ of $95 \%$ alcohol for 10 days, and after drying, powdered in a mortar and fibers removed. Then $77.5 \mathrm{gm}$. of the substance corresponding to $583 \mathrm{gm}$. fresh tissue were extracted by boiling with alcohol repeatedly, until no hot alcohol-soluble substance came out. The extracts were evaporated together under reduced pressure, the appearing crystals being separated half way. The remaining syrup was dried up in a vacuum desiccator $\left(\mathrm{H}_{2} \mathrm{SO}_{4}\right)$ and subjected to ether extraction in a Soxhlet apparatus. On the other hand, the residue after treatment with alcohol was also extracted similarly with ether. And these ether extracts were evaporated together in a shallow wide vessel on a water-bath by the aid of a fan. The brownish syrupy residue (Fr. Es; $18.3 \mathrm{gm}$.) was fractioned with 40 cc. portions (6 portions) of dry acetone. The acetone extracts were evaporated together similar to above, and the remaining yellow oil dried in vacuo. This (Fr. Acs) weighed $13.1 \mathrm{gm}$. The acetone-insoluble residue (brownish resinous substance-Fr. Acn) was divided into parts soluble and inscluble in benzene $^{5)}$ (Frs. Bzs and Bzn; yeilds, 3.8 and $1.4 \mathrm{gm}$.) and the obtained fractions further into parts soluble and insoluble in cold petroleum ether (Frs. Pes and Pen; yields, 3.2 and $0.4 \mathrm{gm}$.) and into parts soluble and insoluble in boiling benzene (Frs. Bzhs and Bzhn; yields, 0.4 and $1.0 \mathrm{gm}$.) respectively.

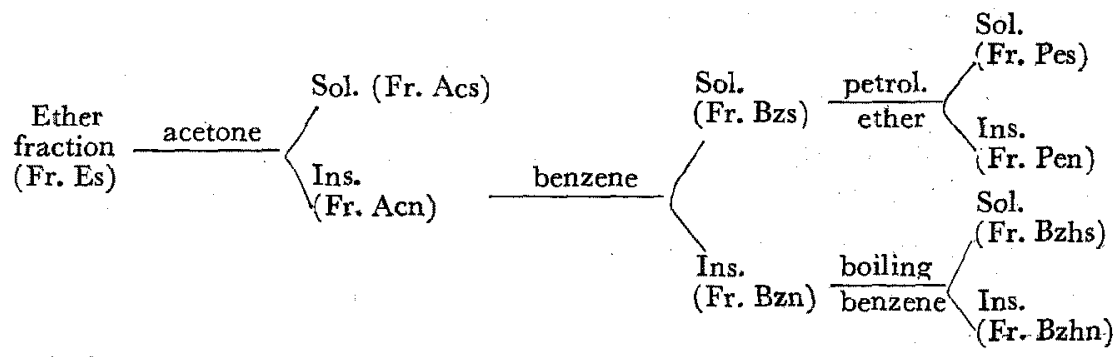

(Solvents, whose temperature is not particularly mentioned, were cold.) 
$\therefore$ The anti-agglutinative power of the above fractions was examined by our usual method, by emulsifying Frs. Pen, Bzhs and Bzhn in physiological saline without and the others with the aid of alkali. The results are embodied in Table I, which shows that the fractions, the acetone-soluble fraction (Acs) excepted, inhibited the agglutination, though non-specifically. The residue after extraction of Es was almost devoid of this potency.

\section{TABLE I.}

Agglutination of A and B Erythrocytes by Normal Antisera Treated with Early Fractions of the Tumor Lipoids.

$A$ and $B$ sera had titres 160 and 80 respectively.

\begin{tabular}{|c|c|c|c|c|c|}
\hline \multirow{2}{*}{ Fraction } & \multicolumn{5}{|c|}{ Dilution of substance } \\
\hline & $\begin{array}{c}1 \% \\
\text { Original }\end{array}$ & $: \times 2$ & $\times 5$ & $\times 10$ & $\times 10^{2}$ \\
\hline
\end{tabular}

Agglutination of A Erythrocytes.

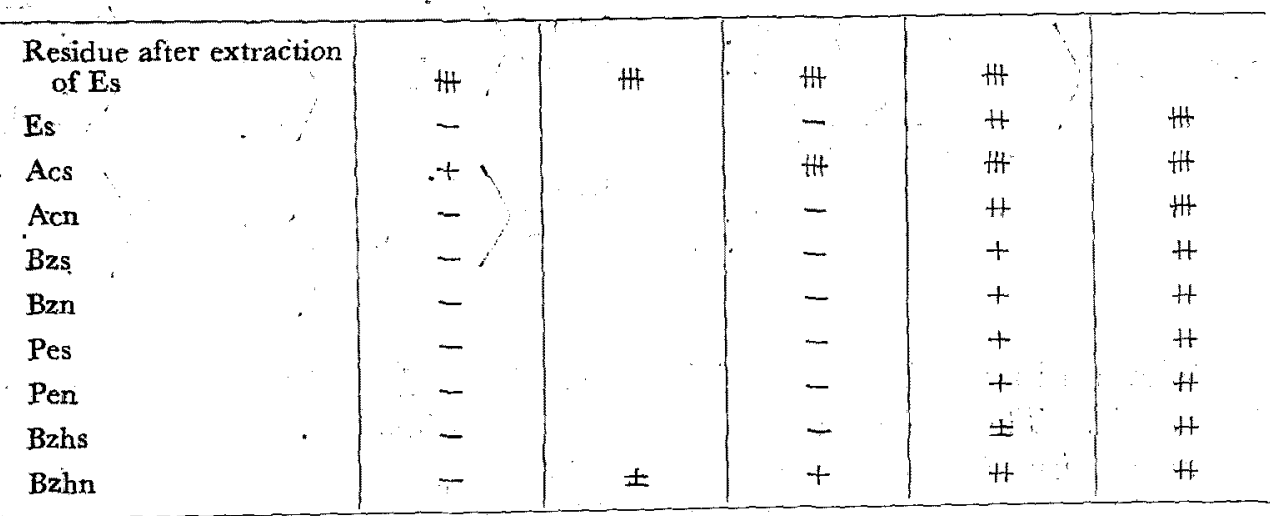

Agglutination of B Brythrocytes.

\begin{tabular}{|c|c|c|c|c|c|}
\hline $\begin{array}{l}\text { Residue after extraction } \\
\text { of } E_{s}\end{array}$ & \pm & + & $H$ & $H$ & \\
\hline Es & - & & - & + & $t$ \\
\hline Acs & + & & Ht & Ht & Hf \\
\hline Acn & - & & - & + & $H$ \\
\hline Bzs & - & & - & + & tt \\
\hline Bzn & - & & - & \pm & H \\
\hline Pes & - & & - & \pm & $H$ \\
\hline Pen & - & & - & - & $H$ \\
\hline Bzhs & - & & - & \pm & $H$ \\
\hline Bzhn & - & - & + & + & $H$ \\
\hline
\end{tabular}

Subdivision of Fr. Pes. It was tried to liberate this fraction (3.2 gm.) completely from cold-acetone-soluble substances. For the purpose, ten 30 cc. changes of acetone were used, each time with subsequent drying. The 
remaining very hygroscopic solid clump-Fr. Pes-acn-weighed $2.3 \mathrm{gm}$. $1 \mathrm{gm}$. of it (the remaining part was lost by mistake) was next fractioned with absolute alcohol (three $30 \mathrm{cc}$. portions), the alcohol extracts evaporated in vacuo and the rest dried after washing (twice) with acetone-Fr. Pes-as. This was treated with boiling acetone (one $30 \mathrm{cc}$. and one $10 \mathrm{cc}$. portion) and the insoluble part taken up in $5 \mathrm{cc}$. benzene (The insoluble part, which was a trace, was discarded.), precipitated with acetone(Nothing remained in the mother liquid.) and, after washing with acetone, dried-Group-specific Substance (S.S.) I (hygroscopic brownish powder); yield, $136.8 \mathrm{mgm}$. The amount of the substance, which had passed over into boiling acetone, was the resembling. The absolute alcohol-insoluble rest-Fr. Pes-anwas washed repeatedly with cold (six $20 \mathrm{cc}$. portions) and boiling (one $30 \mathrm{cc}$. and one $10 \mathrm{cc}$. portion) acetone and, after drying, precipitated from benzene $^{(1)}$ and dried again as was S.S.I-S.S. II (brown powder; $61 \mathrm{mgm}$.).

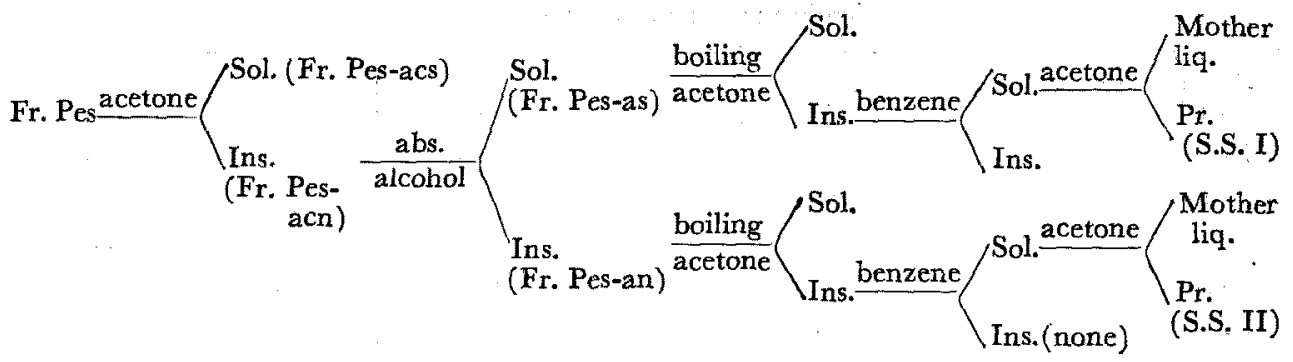

The anti-agglutinative activity was elevated and became specific (Table II). The acetone-soluble fractions were inactive.

Subdivision of Fr. Pen. $330 \mathrm{mgm}$. of this fraction were taken and at first divided into absolute alcohol-soluble (The extracts were evaporated together; the dried up residue (white powder) weighed $267 \mathrm{mgm}$.-Fr. Pen-as.) and -insoluble (brownish powder, $18 \mathrm{mgm}$.-Fr. Pen-an) parts (One $40 \mathrm{cc}$. and two $30 \mathrm{cc}$. portions of alcohol were used.). Both showed specific inhibition of B blood cells from isoagglutination (s. Table III), but due to shortage of material further fractionation of the latter was abandoned, and from the former $251 \mathrm{mgm}$. were taken and extracted with anhydrous benzene (three $40 \mathrm{cc}$. portions). Most of the substance did not dissolve. The insoluble fraction-Fr. Pen-bzn (yellowish solid)-amounted to 190 mgm. and the soluble-Fr. Pen-bzs (yellowish solid) - to $40 \mathrm{mgm}$. Fr. Pen-bzn was treated thoroughly with petroleum ether, acetone and ether. The amount of the remaining brownish powder was $119 \mathrm{mgm}$.-S.S. III.

The stages are schematized in next page, and the serological potencies embodied in Table III.

Subdivision of Fr. Bzhs. From the Bzhs fraction $(0.4 \mathrm{gm}$.$) were re-$ moved acetone-soluble substances (Five $20 \mathrm{cc}$. portions of acetone were 


\section{TABLE II.}

Agglutination of A and B Erythrocytes by Normal Antisera, Treated with Subdivisions of Fr. Pes of the Tumor Lipoids.

The substances were taken up in physiological saline without alkali.

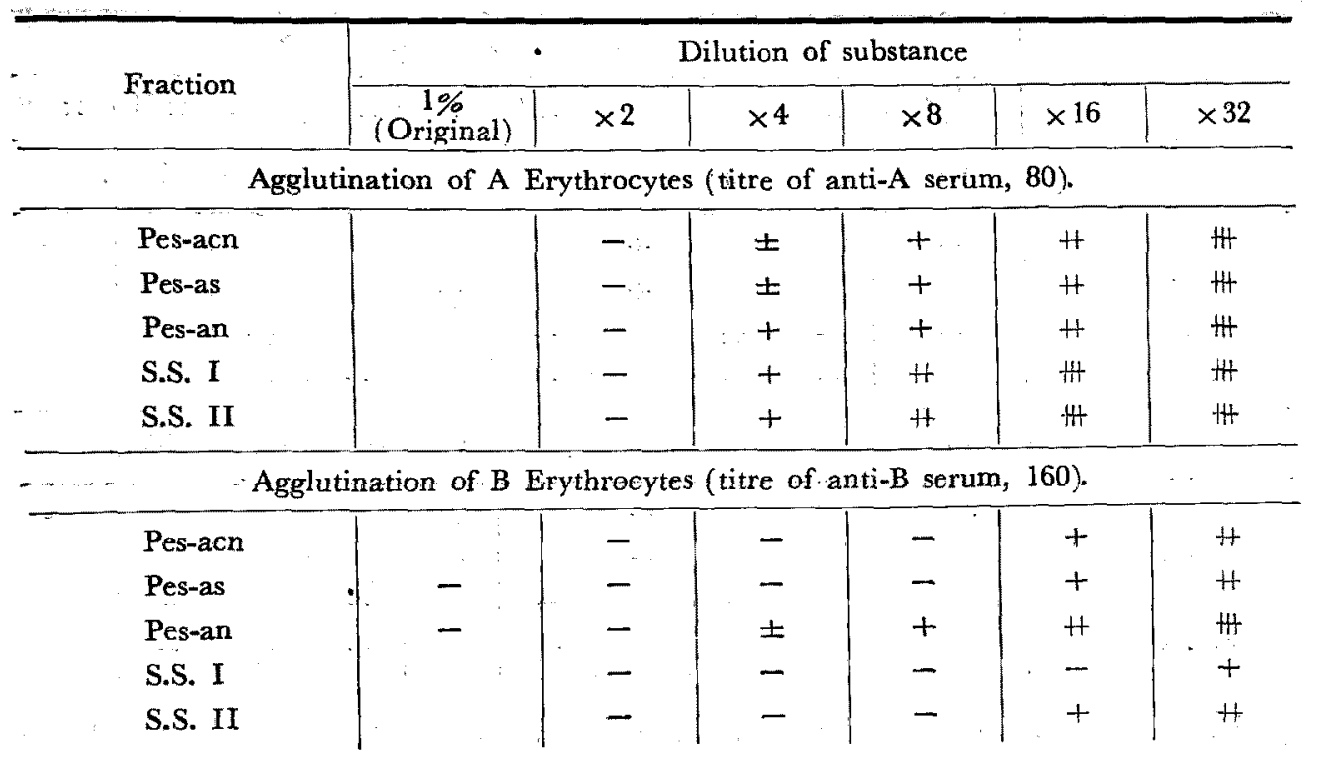

Sol. (Fr. Pen-bzs)

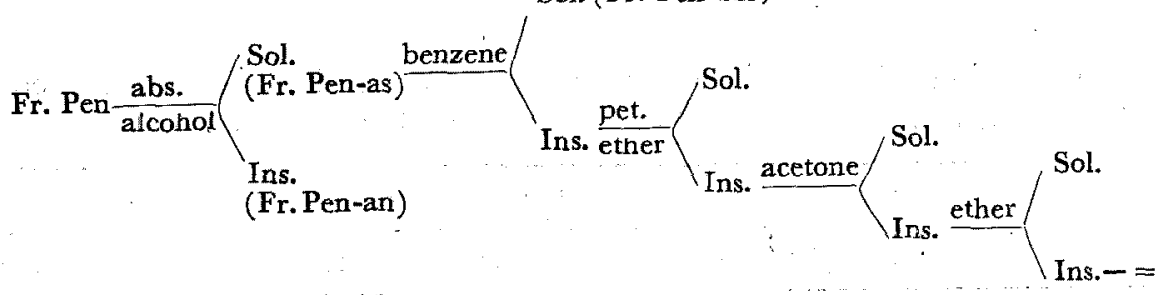

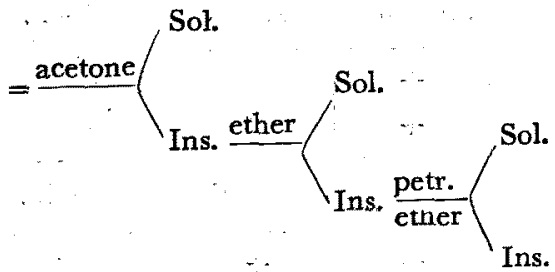

(S.S. III)

used.). The residue contained only a trace of absolute alcohol-soluble substance-Fr. Bzhs-as. After washing with this solvent and drying, the residue-Fr. Bzhs-an-was boiled with a $30 \mathrm{cc}$. and a $10 \mathrm{cc}$. portion of acetone under reflux, and then precipitated from benzene with acetone as were S.S's I and II, and dried in a desiccator-S.S. IV (hygroscopic brownish powder, $43.1 \mathrm{mgm}$.). The fractions, which dissolved in acetone 


\section{TABLE III.}

Agglutination of A and B Erythrocytes by Normal Antisera, Treated with. Subdivisions of Fr. Pen of the Tumor Lipoids.

The substances were taken up in physiological saline without alkali.

\begin{tabular}{c|c|c|c|c|c|c|c|c|c|c}
\hline \multirow{2}{*}{ Fraction } & \multicolumn{8}{|c}{ Dilution of substance } \\
\cline { 2 - 7 } & $\begin{array}{c}1 \% \\
(\text { Original) }\end{array}$ & $\times 2$ & $\times 4$ & $\times 5$ & $\times 8$ & $\times 10$ & $\times 16$ & $\times 32$ & $\times 64$ & $\times 10^{2}$ \\
\hline
\end{tabular}

Agglutination of A Erythrocytes (The employed B serum had agglutinin titre 160.).

\begin{tabular}{|c|c|c|c|c|c|c|c|c|c|c|}
\hline Pen-as & - & : & & + & & $H$ & & & & $H$ \\
\hline Pen-an & - & & & + & & + & & & & $H$ \\
\hline Pen-bzs & - & - & \pm & & + & & $H$ & \# & \# & \\
\hline S.S. III & - & - & - & & + & & + & $H$ & $H$ & \\
\hline
\end{tabular}

Agglutination of B Erythrocytes (The employed A serum had agglutinin titre 160.).

\begin{tabular}{l|l|l|l|l|l|l|l|l|l|l}
\hline Pen-as & - & & & - & & \pm & & & & H \\
Pen-an & - & & & - & & - & $\vdots$ & & & H \\
Pen-bzs & - & - & - & & - & & + & + & H & \\
S.S. III & - & - & - & & - & & - & + & + &
\end{tabular}

(cold and hot), were not active. Table IV shows the potencies of the others.

\section{TABLE IV.}

Agglutination of A and B Frythrocytes by Normal Antisera, Treated with Subdivisions of Fr. Bzhs of the Tumor Lipoids.

\begin{tabular}{|c|c|c|c|c|c|c|}
\hline \multirow{2}{*}{ Fraction } & \multicolumn{6}{|c|}{ Dilution of substance } \\
\hline & $\begin{array}{c}0.5 \% \\
\text { (Original) }\end{array}$ & $\times 2$ & $\times 4$ & $\times 8$ & $\times 16$ & $\times 32$ \\
\hline \multicolumn{7}{|c|}{ Agglutination of A Erythrocytes (Anti-A serum had agglutimin titre 160.). } \\
\hline Bzhs-an & - & \pm & + . & H & H & \\
\hline S.S. IV & - & \pm & + & $\#$ & H & \\
\hline
\end{tabular}

Agglutination of B Erythrocytes (Anti-B serum had agglutinin titre 160.).

\begin{tabular}{l|l|l|l|l|l|l} 
Bzhs-an & - & - & - & + & $H$ & \\
S.S. IV & - & - & - & - & + & $H$
\end{tabular}

Fr. Bzhn. $100 \mathrm{mgm}$. of this were fractioned with absolute alcohol and the insoluble part $(36.0 \mathrm{mgm}$.) furtheron with water (three $2 \mathrm{cc}$. portions). The substances taken up by alcohol (Fr. Bzhn-as) and those taken up by water (Fr. Bzhn-ws) were recovered by evaporation and drying in a desiccator: 62 and $22 \mathrm{mgm}$. were yielded respectively. Present subdivision, 

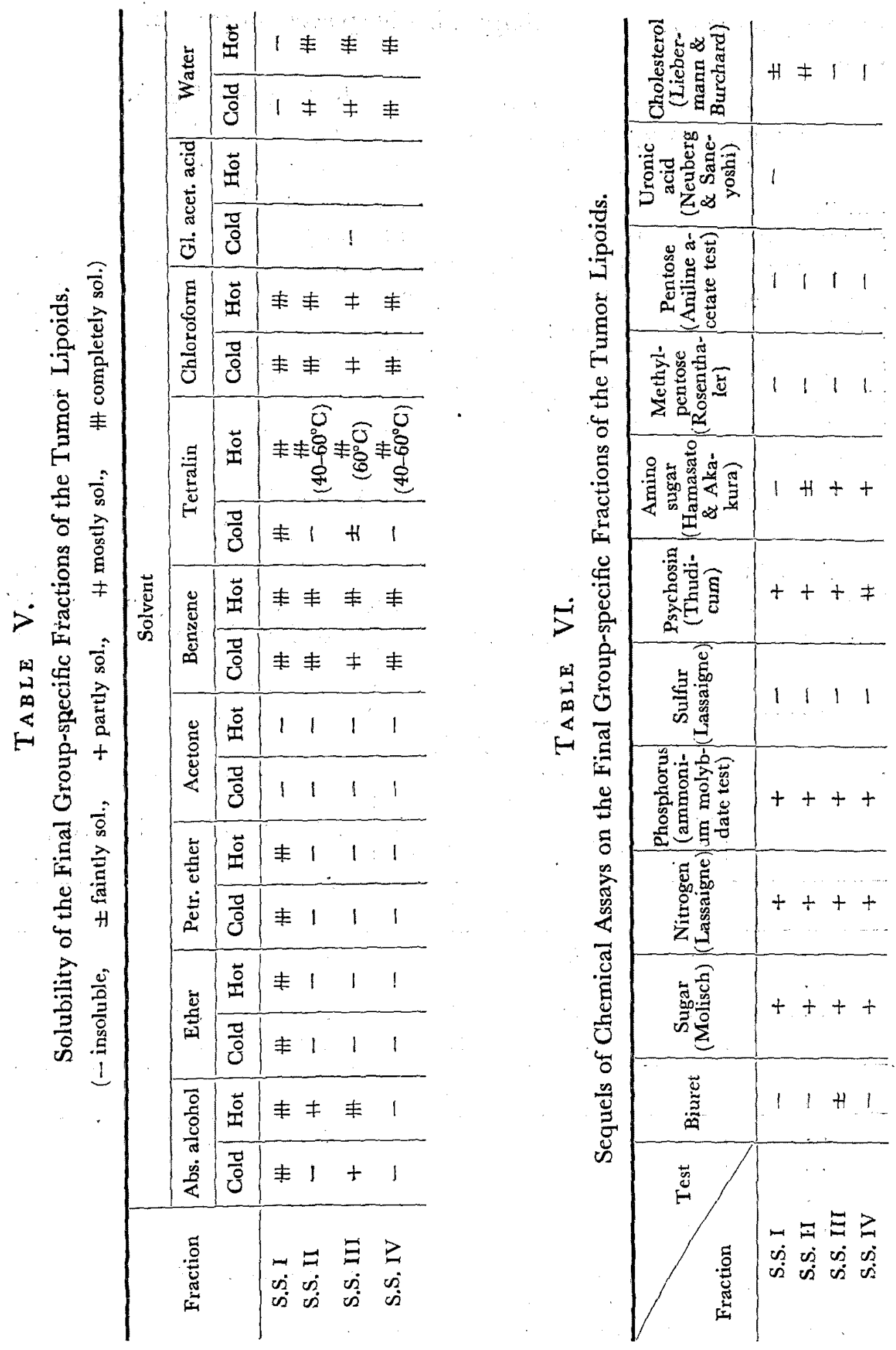
however, did not raise the anti-agglutinative power nor gave rise to specific action.

Solubility of the Group-specific Products (S.S.'s I-IV).

Solubility of S.S.'s is illustrated in Table V.

S.S.I dissolved well in most usual organic solvents except acetone, and did not in water, although it formed an emulsion. However, the other group substances were soluble in water and in particular. S.S.IV gave a complete solution in the cold. These were soluble in benzene and chloroform with ease, but with difficulty in general organic solvents. S.S.'s II and III dissolved in alcohol to different extents and IV did not at all. In short, the group-specific fractions exhibited inorganic character in solubility more and more from left to right in the order of I. III. II. and IV. The watery solutions of S.S.'s II-IV were not precipitated by addition of dilute $\mathrm{HCl}$ to $\mathrm{pH} 2.4$ or less.

Qualitative and Quantitative Chemical Properties of the Groupspecific Products (Tables VI and VII).

All of S.S.'s I-IV gave positive Molisch (for ordinary sugar) and Thudicum (for psychosin) reactions but negative tests for hexuronic acid (Neuberg and Saneyoshi), methylpentose (Rosenthaler), pentose (aniline

$$
\text { TABLE VII. }
$$

Composition of the Final Group-specific Fractions of the Tumor : Lipoids.

\begin{tabular}{|c|c|c|c|c|c|c|}
\hline$\therefore \quad \therefore \quad \therefore$ & \multicolumn{3}{|c|}{ Sugar as galactose } & \multirow{2}{*}{ Phoshorus* } & \multirow[b]{2}{*}{ Nitrogent } & \multirow[b]{2}{*}{ Ash $\ddagger$} \\
\hline . . . & $\begin{array}{c}\text { Indole } \\
r .\end{array}$ & $\begin{array}{c}\text { Orcinol } \\
\text { r. }\end{array}$ & $\begin{array}{l}\text { Diphenyl- } \\
\text { amine } \\
\text { r. I }\end{array}$ & & & \\
\hline$\because \quad \therefore \quad \therefore$ & & \multicolumn{4}{|c|}{ In per cent } & \\
\hline S.S.I & $3.77 \S$ & $1.9 \S$ & & 3.36 & 3.05 & 11.0 \\
\hline S.S. II & & & & 1.07 & 3.63 & 9.08 \\
\hline S.S. III & 7.49 & 6.95 & 7.49 & 2.56 & 5.07 & 7.47 \\
\hline S.S. IV & 16.4 & 13.9 & 15.6 & 2.60 & 3.62 & 8.10 \\
\hline
\end{tabular}

In equivalents per equivalent weight.

\begin{tabular}{l|l|l|l|l|l}
\hline S.S. I & 1.0 & & 5.2 & 10.4 \\
S.S. II & & & 1.0 & 7.5 \\
S.S. III & 1.0 & & 2.0 & 8.7 \\
S.S. IV & 1.0 & & 0.93 & 2.9 &
\end{tabular}

* Haneda, Sinokawa and Yasuoka's modification of Plimmer method.7)

† Micro Kjeldahl method. $\quad$ \$ Micro analysis.

$\S$ The substance was analyzed as an eumlsion in water. 


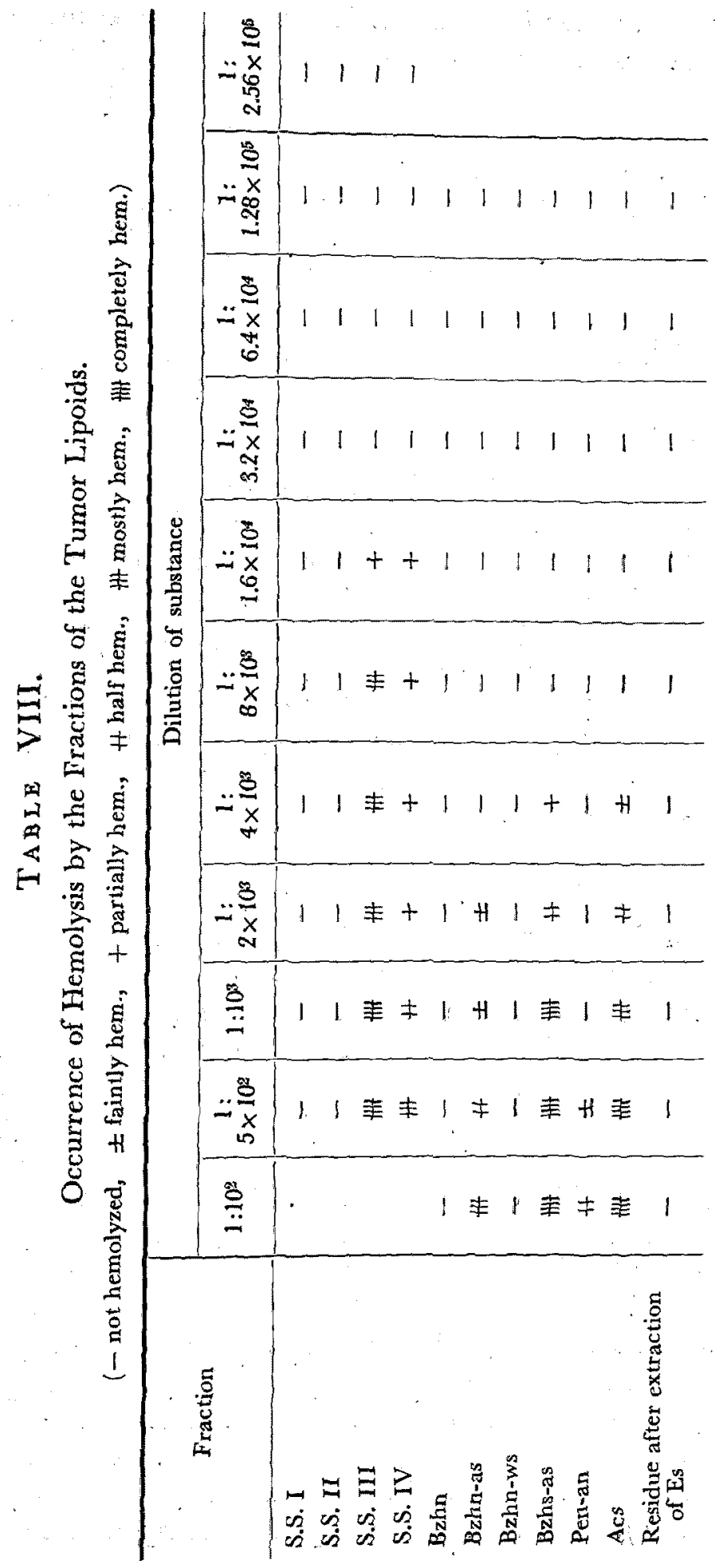


acetate test) and sulfur (Lassaigne). By the analytical method of amino sugar of Hamasato and Akakura, like colouration took place in III and IV as in hexosamine-containing substances. Nevertheless, this is rather ascribed to sphingosin in the molecule, because cerebron and psychosin reacted similarly. S.S. II contained cholesterol (Liebermann-Burchard) in a distinct amount and S. S. I in a minute amount, but the others did not. Exclusive of III, the substances were biuret-negative. In the quantitative respect, nitrogen varied from 3.05 to $5.07 \%$, phosphorus from 1.07 to $3.36 \%$ and sugar as galactose by the indole reaction from 3.77 to $16.4 \%$ (The sugar of S.S.II was not determined.). In sugar analysis, the orcinol method gave lower values than the indole and diphenylamine methods, probably owing to incomplete hydrolysis.

Hemolysis by Fractions of the Tumor Lipoids.

With the aim of examining the hemolytic power, the fractions were taken up in physiological saline (The solutions and emulsions possessed $\mathrm{pH}$ of 5.6-6.0, excluding the emulsion (1\%) of $\mathrm{Fr}$. Bzhs-as whose $\mathrm{pH}$ lay at 4.2.) and progressively diluted with physiological saline. To $0.5 \mathrm{cc}$. of all the solutions and emulsions thus prepared 2 drops of a $3 \%$ erythrocyte suspension were added and the mixture stood in a thermostat at $37^{\circ} \mathrm{C}$ for 3 hours, shaking twice an hour. The sequels are seen in Table VIII. In the control, where physiological saline was used instead of a solution or an emulsion, no hemolysis took place.

\section{Discussion.}

In search for a group-specific lipoid, we have obtained four most active fractions. It will be legitimate here to assume that a single groupactive compound was disseminated among the fractions, owing to the alteration of its solubility by various contaminants. If then, S.S.IV looks to be the purest fraction, for this was free from biuret-positive substances and cholesterol and, at that, contained the largest quantity, calculated from galactose, of psychosin ${ }^{8}$ which appears to be one of the determinant groups in group lipoids (cf. Masamune ${ }^{9}$ ). This fraction was not superior to the others in the anti-agglutinative potency, but the assay employed is not so precise as to distinguish minor differences and moreover a possible co-adsorbens (cf. Hamasato ${ }^{4}$ ) might have enhanced the action of particularly S.S.I, that was poor in psychosin. That the nitrogen content of S.S.IV was more than corresponds to sphingosin (the same applies also to other S.S.'s) supports the hypothesis of Masamune"' on the determinant structures common to all $\mathrm{ABO}$ group substances. Phosphate rests were also present in the group lipoids from blood cells (Hamasato ${ }^{4)}$ ) and normal liver (Matuda ${ }^{(0)}$ ). But with these the present compound is most probably 
not identical, judging from its dissimilar equivalent ratios of sugar : N:P $(1: 3: 2$ in the group lipoids from blood cells and $1: 3: 3$ in those from liver). The accurate relationship will be disclosed by its further purification (s. Second Report).

From the findings here alone, we can not derive any conclusion concerning the grade of differentiation of group lipoids in cancer. In order to dissolve this problem, studies of the group lipoids not only from normal liver but also from gastric cancer and the mucosa of normal stomachs are now being carried on in this Institute.

The Grant Committee for Scientific Researches of the Education Department gave a grant towards the costs of this investigation, which is gratefully acknowledged. H. Masamune.

\section{Bibliography and Notes.}

1) Oh-Uti, K., Tohoku J. Exp. Med., this volume, p. 297.

2) Lattes, Schneider and Beöthy, Wienerklin. Wochens., 1928, 41, 1038.

3) Fisler and Moritsch, Zeits. f. Immun. forsch., 1928, 57, 421.

4) Hamasato, Tohoku J. Exp. Med., in press.

5) Cold dry benzene was used.

6) All the substance dissolved in benzene and was precipitated entirely by acetone.

7) Haneda, Sinokawa and Yásuoka, Tohoku J. Exp. Med., 1944, 46, 263.

8) S. S. II was not analyzed regarding galactose, but it is assumed from its solubility to involve less of the sugar than IV.

9) Masamune, Ketsuekigaku Togikai Hokoku, I, 1948, 180; Tokyo Iji Shinshi, 1949, 66, 269.

10) Matuda, unpublished. 